\title{
Primary Metabolite Profiling of Tinospora cordifolia
}

\section{Abhimanyu Sharma* and Amla Batra}

Plant Biotechnology and Biochemistry Lab, Department of Botany, University of Rajasthan, India

\begin{abstract}
Plants are the sources of many bioactive compounds containing many primary metabolites like, carbohydrates (starch, sugar), proteins, phenols, ascorbic acid etc. are useful for flavoring, fragrances, insecticides, sweeteners and natural dyes (Kaufman). During the present research work, root, stem, leaf and calli of the plant were evaluated quantitatively for the analysis of chlorophyll, sugars, starch, protein, ascorbic acid and phenols. Keeping in view the importance of these primary metabolites the present studies for biochemical evaluation of primary metabolites from different parts of Tinospora cordifolia was undertaken.
\end{abstract}

Keywords: Primary metabolites; Chlorophyll; Sugars; Starch; Protein; Ascorbic acid; Phenols; Tinospora cordifolia

\section{Introduction}

Medicinal plants form the backbone of Traditional System of medicine in India. Pharmacological studies have acknowledged the value of medicinal plants as potential source of bioactive compounds [1]. Phytochemicals from medicinal plants serve as lead compounds in drug discovery and design. Medicinal plants are rich source of novel drugs that forms the ingredients in Traditional System of medicine, modern medicines, nutraceuticals, food supplements, folk medicines, pharmaceutical intermediates, bioactive principles and lead compounds in synthetic drugs. This emerging field is oriented towards the characterisation of small metabolites that act as substrates, products, ligands and signalling entities in cells. Biological systems are under constant challenges from the environment. Adaptation to environmental stimuli is reflected in alterations in the genome, the transcription of genes, the expression level and post-translational modifications of proteins and in the primary and secondary metabolism. Deciphering of the plant metabolome is one of the most difficult analytical tasks in functional genomic research. The term metabolomics stands out from any other organic compound analysis in scale and in chemical diversity, i.e., all metabolites are aimed to be described, both primary and secondary metabolites, present in an organism or biological system. Primary metabolic routes produce primary metabolites, which are present almost everywhere in nature and are essential for all life forms. These compounds include the common carbohydrates, fats, proteins and nucleic acids that are needed to create and maintain life. Apart from fats, the compounds are polymeric and usually chemically large molecules. Typically they are involved in the energy regulation of organisms and with growth and development of tissues; in short, they are the building blocks of organisms. Through the ages, human have relied on nature for their basic needs. Medicinal plants are the most exclusive source of life saving drugs for the majority of the world's population [2]. Primary metabolite analysis is necessary for knowing the nutritional potential of plants and then also from the precursors for the synthesis of secondary metabolites $[3,4]$. Primary plant metabolites are simple molecules or polymers of simple molecules synthesized by plants, generally do not possess therapeutic as such but essential for the life of plants and contain high-energy bonds. These are used up for the biosynthesis of secondary metabolites [5].

Keeping in view the importance of these primary metabolites, during the studies various potent primary metabolites viz., chlorophyll, carbohydrates (sugar, starch), total protein, ascorbic acid and total phenol have been investigated from in vivo root, stem, leaf and in vitro callus in Tinospora cordifolia.

\section{Cholorophyll}

The Chlorophyll is one of the essential components for photosynthesis in plants. They occur in chloroplast as green pigments in all the photosynthetic tissues. Chemically, each chlorophyll molecule contains a porphyrin nucleus with a chelated magnesium atom at the centre and a long chain hydrocarbon attached through a carboxylic group. The different types of chlorophyll like chlorophyll a, b and carotenoids are present in a whole pigment extract of green plant tissues (Figure 1).

Principle: Chlorophyll is extracted and the absorption at $663 \mathrm{~nm}$ and $645 \mathrm{~nm}$ are read using spectrophotometer. Using the absorption coefficient the amount of chlorophyll is calculated by Arnon's method, 1949, using the formula:

$$
\begin{aligned}
& \text { Chlorophyll } a=\frac{(12.3 \times \text { O.D. at } 663-0.86 \times O . D \text {. at } 645) \times V}{1000 \times W} \\
& \text { Chlorophyll } b=\frac{(19.3 \times O . D \text {. at } 645-3.6 \times \text { O.D. at } 663) \times V}{1000 \times W}
\end{aligned}
$$

Total chlorophyll $=\mathrm{a}+\mathrm{b}$

Where,

$\mathrm{V}=$ Final volume of chlorophyll extract in $80 \%$ acetone

$\mathrm{W}=$ Fresh weight of tissue extracted

Material: Dilute analytical grade acetone to $80 \%$ prechilled acetone.

\section{Method}

Extraction: $1 \mathrm{gm}$ of plant material was crushed in chilled 80\% acetone and extracted thrice by centrifugation at $5000 \mathrm{rpm}$ for 5 minutes. All the supernatants were pooled and the volume of the extract was made up to $4 \mathrm{ml}$.

Estimation: Absorbance of this solution was read at 645 and

*Corresponding author: Abhimanyu Sharma, Plant Biotechnology and Biochemistry Lab, Lab No 5, Department of Botany, University of Rajasthan, India, E-mail: abhsbiotech87@gmail.com

Received April 20, 2016; Accepted May 09, 2016; Published May 15, 2016

Citation: Sharma A, Batra A (2016) Primary Metabolite Profiling of Tinospora cordifolia. Nat Prod Chem Res 4: 221. doi:10.4172/2329-6836.1000221

Copyright: @ 2016 Sharma A, et al. This is an open-access article distributed under the terms of the Creative Commons Attribution License, which permits unrestricted use, distribution, and reproduction in any medium, provided the original author and source are credited. 


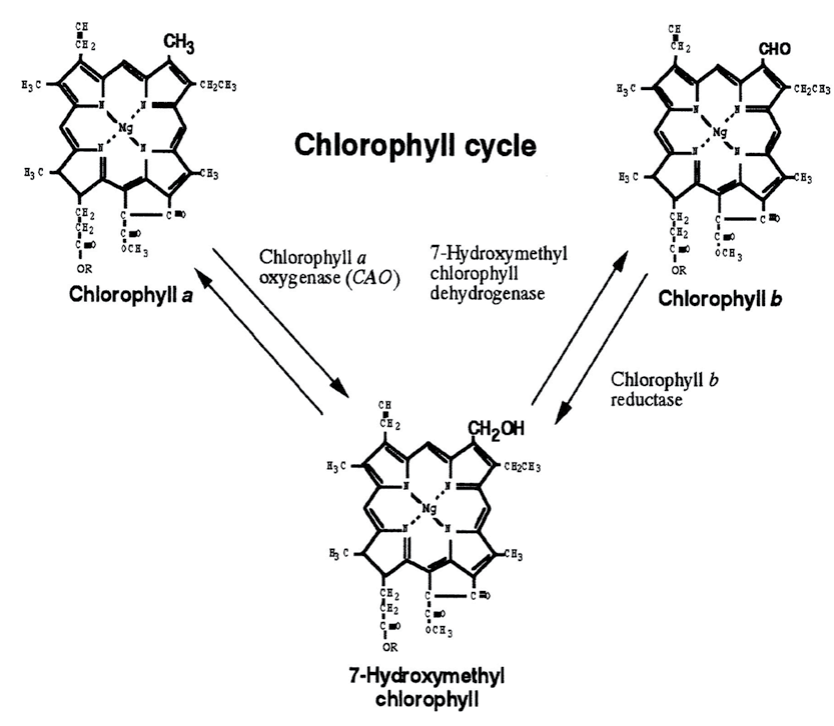

Figure 1: Synthesis of Chlorophyll in plants.

$663 \mathrm{~nm}$ against $80 \%$ acetone used as blank. Results presented were average of three replicates.

Results: Different amount of chlorophyll a content was observed in various plant parts used in the plant, which are summarized in the following manner (Graph 1).

Different amount of chlorophyll b content was observed in various plant parts used in Tinospora cordifolia, which are summarized in the following manner (Graph 2).

\section{Carbohydrates}

Carbohydrates are widely prevalent in the plant kingdom, comprising the mono-, di-, oligo-, and polysaccharides. The common monosaccharides are glucose, fructose, galactose, ribose etc. The disaccharides i.e., the combination of two monosaccharides include sucrose, lactose and maltose etc. Starch and cellulose are polysaccharides consisting of many monosaccharide residues. Cellulose is the most abundant organic compound on this planet, since it forms the part of the cell wall in plants.

Some carbohydrates are digestible by humans and therefore provide an important source of energy, whereas others are indigestible and therefore do not provide energy. Indigestible carbohydrates form part of a group of substances known as dietary fiber, which also includes lignin. Consumption of significant quantities of dietary fiber has been shown to be beneficial for human nutrition, help to reduce the risk of certain types of cancer, coronary heart disease, diabetes and constipation. Being an important source of energy and dietary fiber, carbohydrates also contribute to the sweetness, appearance and texture characteristics of many foods. Plants take about one quarter of the carbon dioxide found in the atmosphere and convert it into simple sugars (carbohydrates) through photosynthesis. It is important to determine the type and quantity of carbohydrates in foods for health purpose (Figure 2).

Principles: Carbohydrates are estimated by Anthrone's method [6]. They are hydrolysed in to simple sugars by dilution in acidic medium. Glucoses dehydrated to hydroxyl methyl furfural. This compound with anthrone forms a green coloured product with absorption maximum at $630 \mathrm{~nm}$.

\section{Materials and methods}

\section{Materials}

1. Anthrone reagent: Dissolve $200 \mathrm{mg}$ anthrone in $100 \mathrm{ml}$ ice cold $95 \% \mathrm{H}_{2} \mathrm{SO}_{4}$ (freshly prepared).

2. $80 \%$ ethanol

3. $2,3 \mathrm{~N}-\mathrm{HCl}$

4. Standard glucose

Stock solution: 10 gm glucose was dissolved in $10 \mathrm{ml}$ of distilled water.

Working Standard

Dilution Series were made from 0.05 to $0.1 \mathrm{mg} / \mathrm{l}$

$1.0 .1 \mathrm{mg} / \mathrm{ml}=1.0 \mathrm{ml}$ of stock standard

2.0.075 mg/ml=0.75 $\mathrm{ml}$ of stock standard $+0.25 \mathrm{ml}$ of distilled water

$3.0 .05 \mathrm{mg} / \mathrm{ml}=0.5 \mathrm{ml}$ of stock standard $+0.5 \mathrm{ml}$ of distilled water

$4.0 .025 \mathrm{mg} / \mathrm{ml}=0.25 \mathrm{ml}$ of stock standard $+0.75 \mathrm{ml}$ of distilled water

$5.0 .05 \mathrm{mg} / \mathrm{ml}=0.05 \mathrm{ml}$ of stock standard $+0.95 \mathrm{ml}$ of distilled water

\section{Procedure}

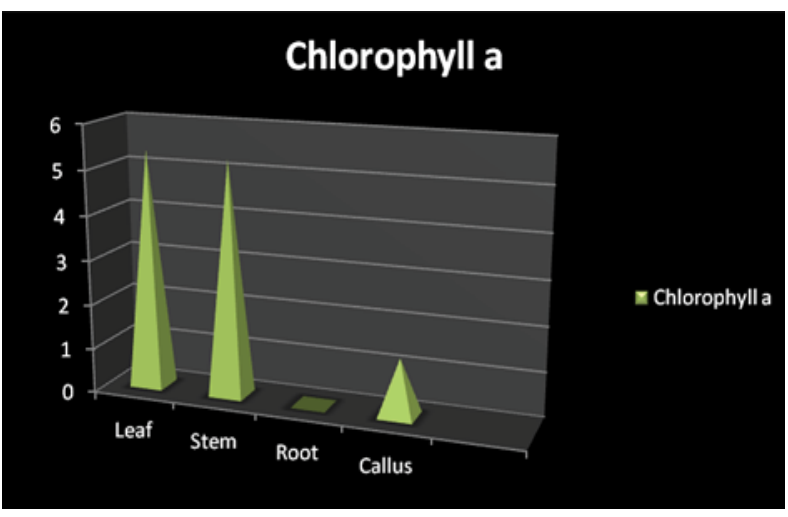

Graph 1: Chlorophyll a content in different parts of Tinospora cordifolia.

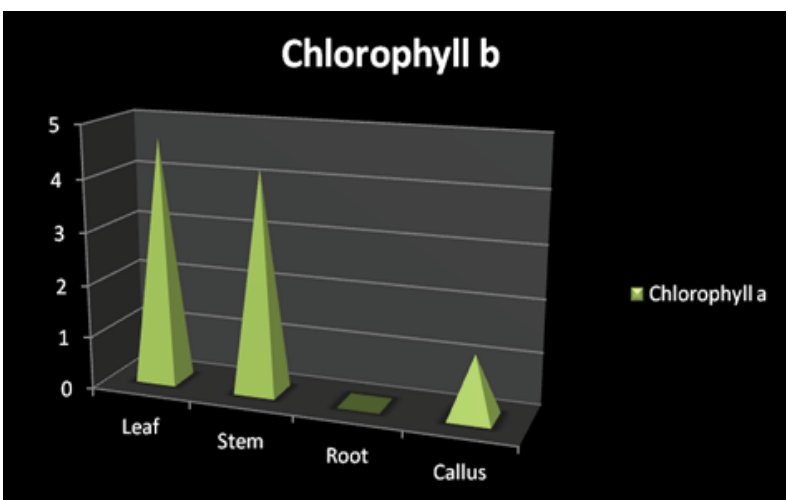

Graph 2: Chlorophyll b content in different parts of Tinospora cordifolia. 


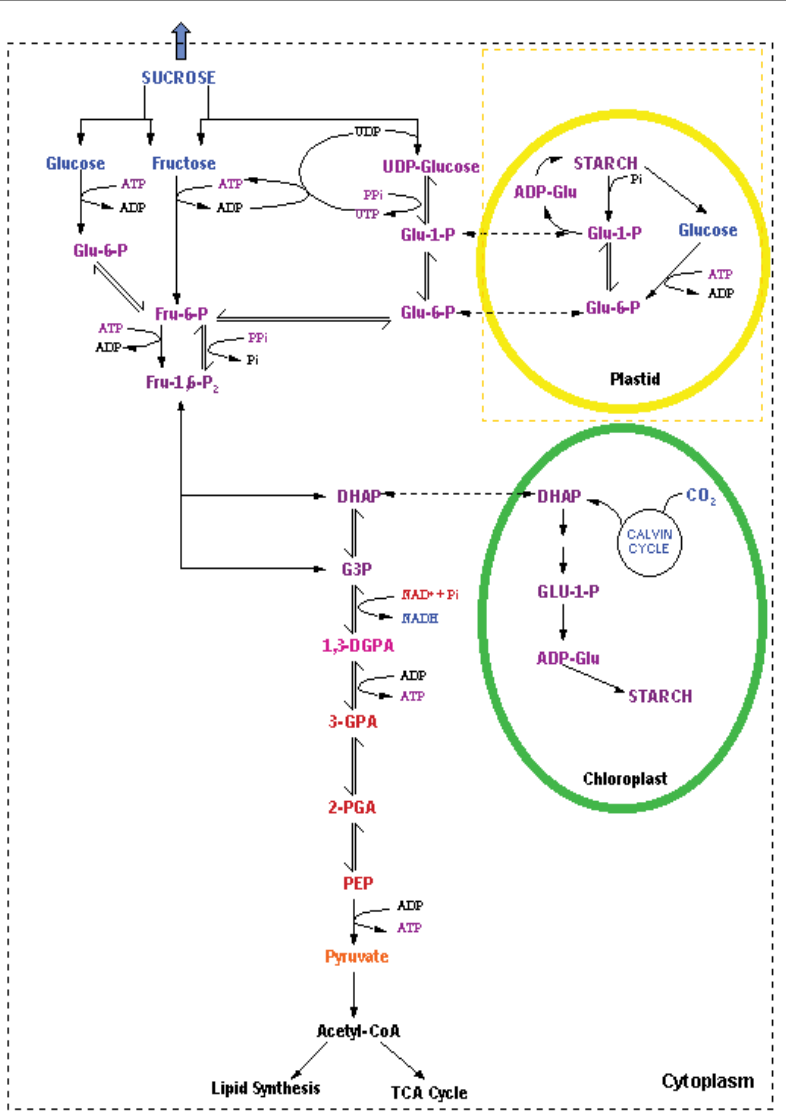

Figure 2: Carbohydrate synthesis in plants.

\section{Method of extraction}

\author{
Plant Sample (1 mg) \\ $\downarrow$ \\ Macerated in $80 \%$ ethanol $(10 \mathrm{ml})$ \\ $\downarrow$
}

Centrifuged at $3000 \mathrm{rpm}$ for $10-15 \mathrm{~min}$

$\downarrow$

Supernatant was saved

\section{Estimation}

1. Take $1.0 \mathrm{ml}$ of aliquot and add $2.0 \mathrm{ml}$ of anthrone reagent.

2. Heat the mixture in water bath for 12 minutes and then cool.

3. OD was recorded at $630 \mathrm{~nm}$.

4. Reference curve was prepared by using glucose.

5. Three replicates were taken and carbohydrate contents were expressed as $\mathrm{mg} / \mathrm{ml}$ of tissues.

Results: Different amounts of sugar were observed in various plant parts used in this plant, which are summarized in the following manner (Graph 3).

\section{Starch}

Starch is biodegradable and renewable in nature. Starch is the major carbon reserve in most plants. It is a mixture of amylose and amylopectin and is deposited as granules inside plastids (chloroplasts in leaf, amyloplasts in non-photosynthetic tissues). The initial attack on starch granules in leaf and non-photosynthetic tissues is by $\alpha$-amylase and a debranching enzyme (Figure 3 ).

They are increasingly being considered as an eco-friendly alternative to the use of synthetic additives in many other products, including plastics, detergents, pharmaceutical tablets, pesticides, cosmetics and even oil-drilling fluids [7].

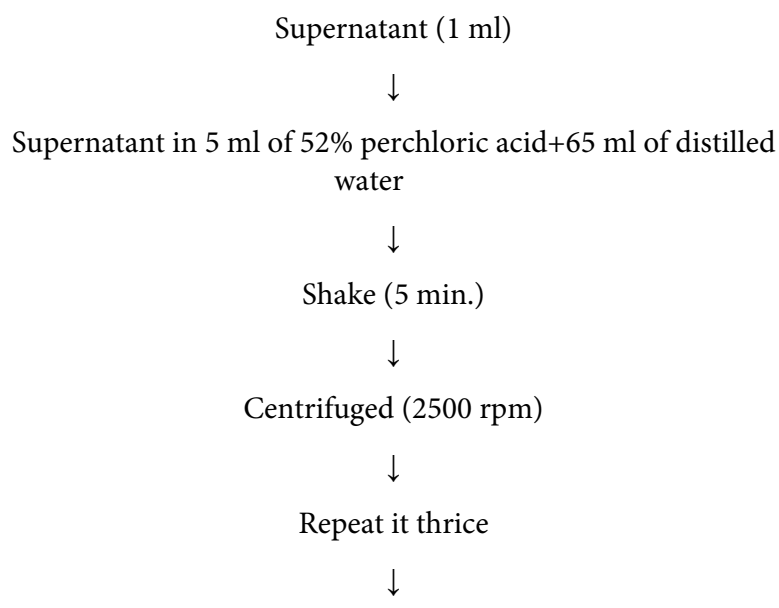

Supernatant of the sample was pooled and the volume was raised to $100 \mathrm{ml}$ with distilled water

$\downarrow$

$1 \mathrm{ml}$ of aliquot was separated

Results: Varying amount of starch contents was observed in various plant parts used in Tinospora cordifolia, which given in following way (Graphs 4 and 5).

\section{Proteins}

Proteins are the primary components of living being. The presence of higher protein level in the plants towards the possible increase in food value as reported [8]. Protein is an important part of life and nutrition; it is the substance that composes a large portion of body's structure. Proteins are made up of amino acids arranged in different combinations. Next to water, protein is the most abundant substance in the human body. It is a part of all body cells and is a vital building block for growth, maintenance and repair of the body tissues (Figure 4).

Principle: It has been estimated by Lowry et al. [9]. The blue

\section{Carbohydrate content in gm/gdw}

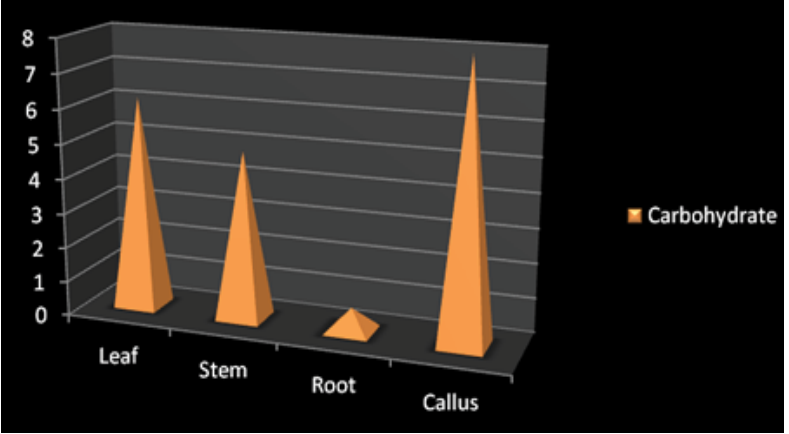

Graph 3: Carbohydrate content in different plant parts of Tinospora cordifolia 


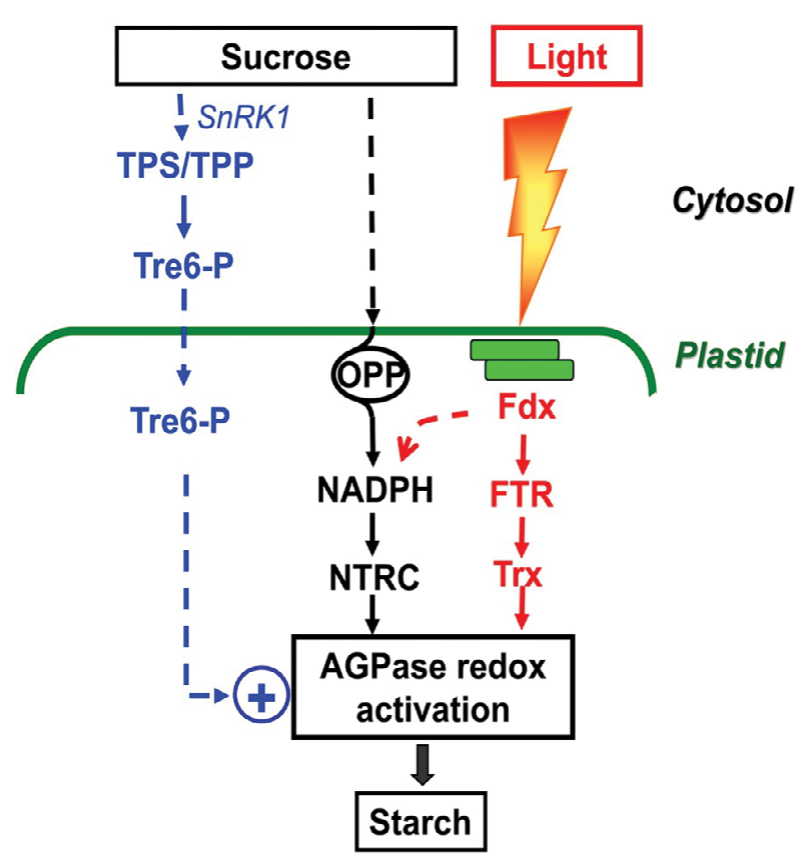

Figure 3: Synthesis of Starch in plants.

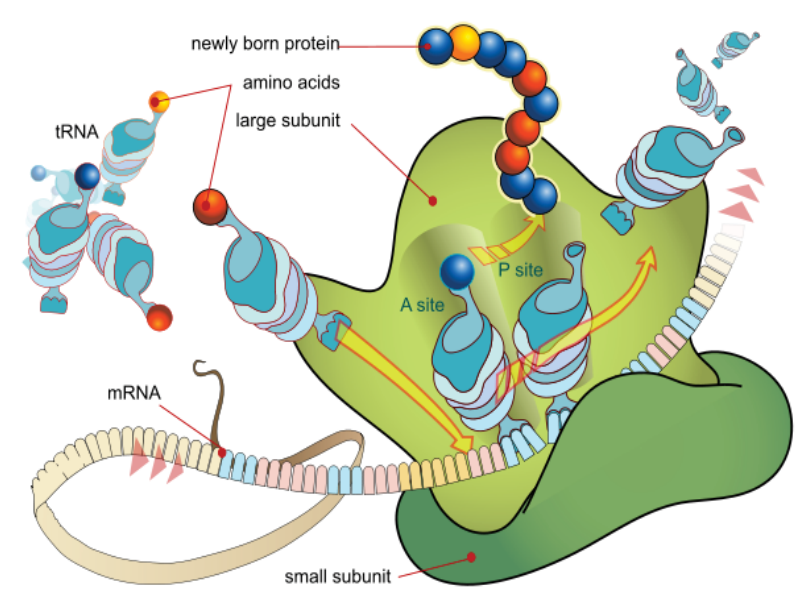

Figure 4: Synthesis of Proteins.

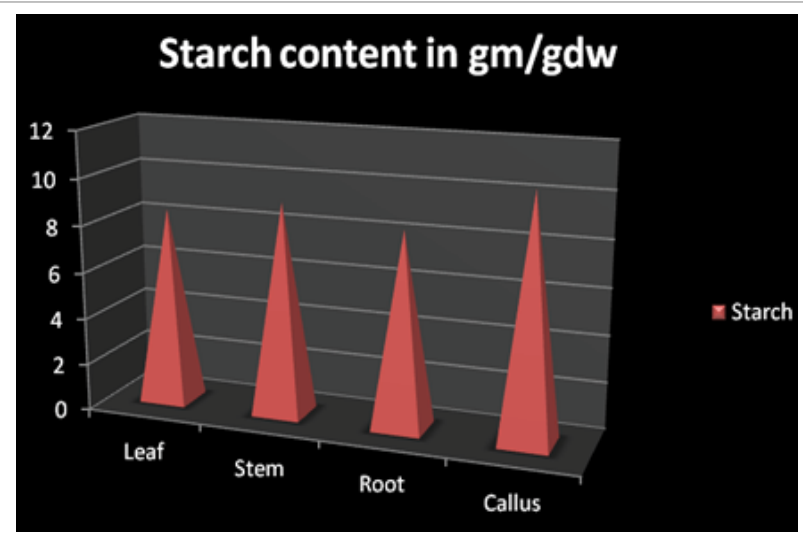

Graph 4: Starch content in different plant parts of Tinospora cordifolia.

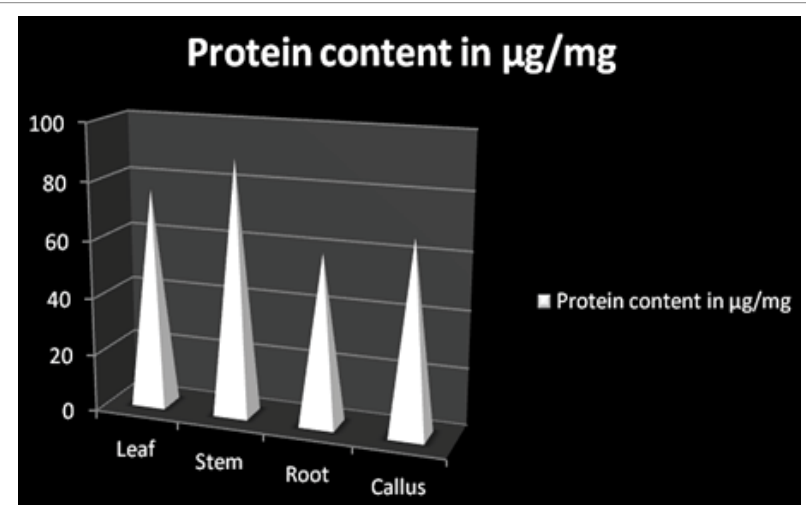

Graph 5: Protein content in different plant parts of Tinospora cordifolia.

colour developed by the reduction of the phosphomolydicphoshpho tungstic components in the Folin- Ciocalteau reagent by the amino acid, trysoine and tryptophan in the protein.

\section{Materials and methods}

\section{Chemicals}

1. Reagent A: $2.0 \%$ sodium carbonate in $0.1 \mathrm{~N}$ sodium hydroxide.

2. Reagents B: $0.5 \%$ copper sulphate $\left(\mathrm{CuSO}_{4} \cdot 5 \mathrm{H}_{2} 0\right)$ in $1 \%$ potassium sodium tartarate.

3. Reagent C: $50 \%$ of reagent $\mathrm{A}+1.0 \mathrm{ml}$ of reagent $\mathrm{B}$.

4. Reagent D: Folin-Ciocalteau reagent

5. Protein Solution: Protein standard solution was made by dissolving $50 \mathrm{mg}$ BSA (bovine serum albumin) in distilled water, final volume was made up to $50 \mathrm{ml}$.

6. Working Standard: $10 \mathrm{ml}$ of stock solution was diluted by adding $40 \mathrm{ml}$ of distilled water. Concentration range $10 \mu \mathrm{g}-200 \mu \mathrm{g}$ proteins was prepared from this by making a series range from $0.1-1.0$ $\mathrm{ml}$ of solution.

\section{Procedure}

\section{Method of extraction \\ Plant Sample (1 mg)}

Macerated in $80 \%$ ethanol (10 ml)

\section{Centrifuged at $3000-4000 \mathrm{rpm}$ for $10-15 \mathrm{~min}$}

Supernatant discarded and residue was pooled

Residue was suspended in 5\% perchloric acid

Recentrifuged at $3000 \mathrm{rpm}$ for $10-15 \mathrm{~min}$.

Residue was pooled and supernatant discarded 
$\downarrow$

Residue was resuspended in mixture of ethanol, ether and chloroform $(2: 1: 1)$

\section{$\downarrow$}

Residue was again centrifuged and washed with $1 \mathrm{~N}$ cold TCA (Trichloro acetic acid)

$$
\downarrow
$$

Recentrifuged

$\downarrow$

Again supernatant was discarded and pellet was dissolved in $1 \mathrm{~N}$ $\mathrm{NaOH}$

$\downarrow$

Made up the solution and incubated for 1 hour at room temperature

\section{Estimation}

1. Added $5 \mathrm{ml}$ of reagent $\mathrm{C}$ in $0.1 \mathrm{ml}$ of residue.

2. Then added $0.5 \mathrm{ml}$ of reagent $\mathrm{D}$ and incubated at room temperature for $30 \mathrm{~min}$.

3. Blue colour developed and its OD was measured at $660 \mathrm{~nm}$.

4. Standard curve was prepared with BSA (Bovine serum albumin) and three replicates were taken for each estimation.

5. Protein contents were expressed in terms of $\mu \mathrm{g} / \mathrm{gm}$ fresh weight.

\section{Results}

Different amount of proteins was observed in various plant parts used in this plant, summarized in the following order:

Ascorbic acid: Ascorbic acid is also known as "Vitamin C" is an antiscorbutic. Usually, it is present in all fresh vegetables and fruits. It is water soluble and heat liable vitamin. It promotes seed germination, growth and flowering in plants. Besides, it also stimulates amylase, protease and RNA activity in various crops. It is found in actively metabolizing cells. Ascorbic acid (vitamin C) is a familiar molecule because of its dietary significance, most aspects of its metabolism and some aspects of its functions in plants are very poorly understood [10] (Figure 5).

Principle: Norit reagent is used in this method, which oxidizes ascorbic acid in the presence of Trichloro acetic acid.

\section{Materials and Methods}

\section{Reagents}

I. 2\% 2,4-dinitrophenyl hydrazine: $2 \mathrm{gm}$ of compound dissolved in $100 \mathrm{ml}$ of $9 \mathrm{~N} \mathrm{H}_{2} \mathrm{SO}_{4}$.

II. Norit reagent: $2 \%$ activated charcoal (Norit) dissolved in 100 $\mathrm{ml}$ of 6\% TCA. It was filtered through Whatman filter paper No. 42.

III. $10 \%$ Thiourea: 10 gm of thiourea dissolved in $100 \mathrm{ml}$ of $90 \%$ alcohol.

IV. Standard ascorbic acid solution: $50 \mathrm{mg}$ of ascorbic acid was dissolved in $50 \mathrm{ml}$ of distilled water. A concentration range from 10 $\mu \mathrm{g}-100 \mu \mathrm{g}$ of ascorbic acid by undertaking a volume series from 0.1-1.0 $\mathrm{ml}$ of the standard solution was prepared.

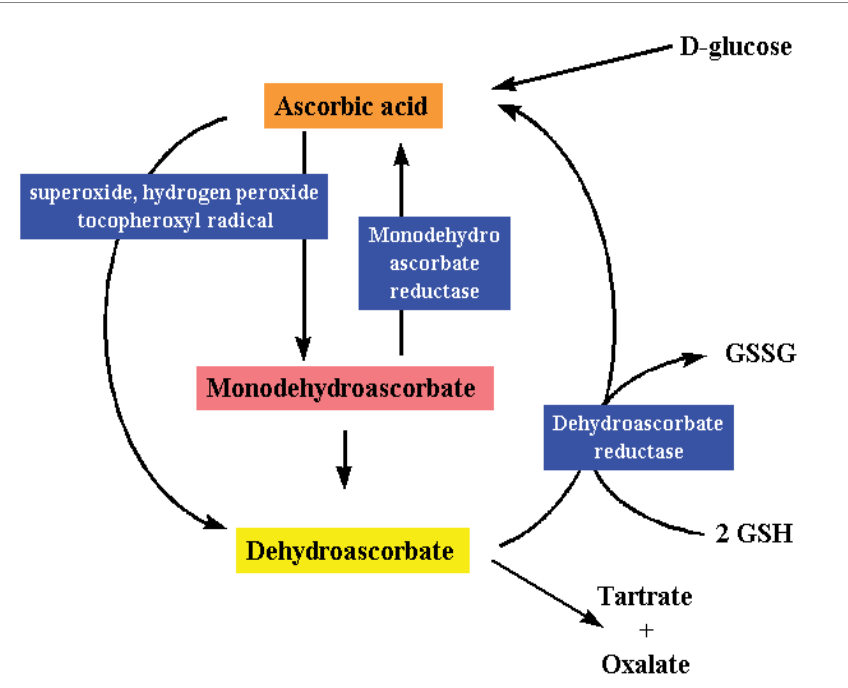

Figure 5: Synthesis of Ascorbic Acid.

\section{Procedure}

Method of extraction

$$
\begin{gathered}
\text { Plant sample }(500 \mathrm{mg}) \\
\downarrow \\
\text { Macerated in Norit reagent }(10 \mathrm{ml}) \\
\downarrow \\
\text { Centrifuged at } 1000 \mathrm{rpm} \text { for } 10-15 \mathrm{~min} \\
\downarrow \\
\text { Supernatant was pooled }
\end{gathered}
$$

\section{Estimation}

1. $1.0 \mathrm{ml}$ of 2-4 dinitrophenyl hydrazine was added to $4.0 \mathrm{ml}$ of the prepared solution.

2. At the same time, one drop of thiourea was added to it and the reaction mixture was boiled for $15 \mathrm{~min}$ at $100^{\circ} \mathrm{C}$.

3. This was followed by dipping these tubes in ice bath for cooling.

4. In this reaction mixture, $5.0 \mathrm{ml}$ of $85 \%$ sulphuric acid was added and subjected to an incubation period of 30 minutes.

5. Different concentrations of ascorbic acid (ranging from $10 \mu \mathrm{g}$ $-100 \mu \mathrm{g}$ ) were used to prepare the standard curve.

6. Three replicates were taken and content of ascorbic acid was expressed in terms of $\mu \mathrm{g} / \mathrm{mg}$ fresh weight of the tissue.

Results: Ascorbic acid concentration was different in various plant parts of Tinospora cordifolia are narrated in the following manner:

Callus $(49.11 \mathrm{gm} / \mathrm{gdw})>$ Leaf $(43.19 \mathrm{gm} / \mathrm{gdw})>$ Root $(42.08 \mathrm{gm} /$ gdw) $>$ Stem $(38.9$ gm/gdw)

\section{Total phenol}

Phenols are very stable products in plant organisms. Generally, they are characterized by a benzene ring having one hydroxyl group $(-\mathrm{OH})$ at its ortho position. They can be converted into lignin, which is the main phenolic polymer in plants. Grains and seeds containing high amount of polyphenols are resistant to bird attack. It includes an 
array of compounds like tannins, flavonoids etc. Phenolic compounds occur in a variety of simple and complex forms. They are oxidized by oxidative enzymes such as peroxidases and phenol oxidizes.

Principle: Phenolic contents were measured by the method of Mahadevan [11]. Phenols react with phosphomolybdic acid in Folin Ciocalteau reagent in alkaline medium and produce blue coloured complexes (Molybdenum blue).

\section{Material and methods}

Reagents

- $80 \%$ ethanol

- Folin Ciocalteau reagent

- $20 \%$ sodium carbonate $\left(\mathrm{Na}_{2} \mathrm{CO}_{3}\right)$

- Standard phenol solution

Stock standard: $50 \mathrm{mg}$ Catechol dissolved in $50 \mathrm{ml}$ of distilled water.

Working Standard: $10 \mathrm{ml}$ of stock standard was diluted to $100 \mathrm{ml}$ for preparing of working standard. A series of volume from $0.1-1.0 \mathrm{ml}$ of this standard gives a concentration range from $10 \mu \mathrm{g}-100 \mu \mathrm{g}$ and proceeded as that of the sample.

\section{Procedure}

\section{Method of extraction}

Plant sample (500 mg)

$\downarrow$

Homogenized in $80 \%$ ethanol $(10 \mathrm{ml})$

$\downarrow$

Centrifuged at 1000-3000 rpm for $20 \mathrm{~min}$

$\downarrow$

Supernatant was saved and residue was re-extracted with $80 \%$ ethanol

$\downarrow$

Centrifuged

$\downarrow$

Supernatant was pooled

\section{Estimation}

- Pipette out $2.0 \mathrm{ml}$ of aliquot in to a test tube.
- It was made $3.0 \mathrm{ml}$ with distilled water.

- Added $0.5 \mathrm{ml}$ of Folin- Ciocalteau reagent.

- After 3 minutes, $2.0 \mathrm{ml}$ of $20 \% \mathrm{Na}_{2} \mathrm{CO}_{3}$ solution was added.

- Mixed thoroughly and the tubes were placed in boiling water for exactly one minute. After cooling OD or absorbance at $650 \mathrm{~nm}$ against blank was taken.

- Standard curve was prepared by using different concentrations of stock standard.

- Three replicates were taken and total phenols were expressed in terms of $\mu \mathrm{g} / \mathrm{mg}$ fresh weight.

Results: Amount of phenol contents varied with the type of explant used as summarized in the following manner:

Stem $(77.56 \mathrm{gm} / \mathrm{gdw})>$ Callus $(61.34 \mathrm{gm} / \mathrm{gdw})>$ Leaf $(53.16 \mathrm{gm} /$ $\mathrm{gdw})>\operatorname{Root}(44.21 \mathrm{gm} / \mathrm{gdw})$

\section{Discussion}

Plants are the sources of many bioactive compounds containing many primary metabolites like, carbohydrates (starch, sugar), proteins, phenols, ascorbic acid etc. are useful for flavoring, fragrances, insecticides, sweeteners and natural dyes [12]. During the present research work, root, stem, leaf and calli of the plant were evaluated quantitatively for the analysis of chlorophyll, sugars, starch, protein, ascorbic acid and phenols. Keeping in view the importance of these primary metabolites the present studies for biochemical evaluation of primary metabolites from different parts of Tinospora cordifolia was undertaken (Table 1). In the present investigation, it was observed that maximum amount of Chlorophyll $a$ and chlorophyll $b$ and is found in leaf and minimum in root of Tinospora cordifolia. In consonance to this Rainha et al. [13] also found best result in the anatomical part of Hypericum foliosum. In contrats to this Havsteen [14], found maximum chlorophyll result in callus of Triticum aestivum and other medicinally important plants.

During the present investigation, it was observed that maximum sugar is found in callus and minimum in root of the plant. In consonance to this Singh et al. [15] also showed maximum amount of sugar in in vitro derived callus of Commiphora wightii and Andrographis paniculata, respectively. Furthermore, root part of Andrographis paniculata also reported to have appreciable amount of sugar [16], which is also in favour of our studies However, in contrast to our findings Leaf and flower of $N$. indicum showed higher soluble sugar as compared to other plant parts investigated by Vijayvergia and Kumar [4].

\begin{tabular}{|c|c|c|c|c|}
\hline Primary & Leaf & Stem & Callus & Root \\
\hline Chlorophyll a & $5.37 \pm 0.29 \mathrm{gm} / \mathrm{gdw}$ & $5.27 \pm 0.39 \mathrm{gm} / \mathrm{gdw}$ & $1.28 \pm 0.58 \mathrm{gm} / \mathrm{gdw}$ & 0.0 \\
\hline Chlorophyll b & $4.67 \pm 0.57 \mathrm{gm} / \mathrm{gdw}$ & $4.23 \pm 0.59 \mathrm{gm} / \mathrm{gdw}$ & $1.18 \pm 0.006 \mathrm{gm} / \mathrm{gdw}$ & 0.0 \\
\hline Carbohydrates & $6.17 \pm 0.65 \mathrm{gm} / \mathrm{gdw}$ & $4.87 \pm 0.39 \mathrm{gm} / \mathrm{gdw}$ & $7.96 \pm 0.24 \mathrm{gm} / \mathrm{gdw}$ & $0.67 \pm 0.12 \mathrm{gm} / \mathrm{gdw}$ \\
\hline Starch & $8.44 \pm 0.48 \mathrm{gm} / \mathrm{gdw}$ & $9.10 \pm 0.63 \mathrm{gm} / \mathrm{gdw}$ & $10.37 \pm 0.37 \mathrm{gm} / \mathrm{gdw}$ & $8.36 \pm 0.52 \mathrm{gm} / \mathrm{gdw}$ \\
\hline Proteins & $76.06 \pm 0.33 \mu \mathrm{g} / \mathrm{mg}$ & $88.57 \pm 0.29 \mu \mathrm{g} / \mathrm{mg}$ & $67.09 \pm 0.47 \mu \mathrm{g} / \mathrm{mg}$ & $59.33 \pm 0.36 \mu \mathrm{g} / \mathrm{mg}$ \\
\hline Ascorbic Acid & $47.63 \pm 0.4 \mu \mathrm{g} / \mathrm{mg}$ & $32.89 \pm 0.68 \mu \mathrm{g} / \mathrm{mg}$ & $61.17 \pm 0.90 \mu \mathrm{g} / \mathrm{mg}$ & $39.77 \pm 0.62 \mu \mathrm{g} / \mathrm{mg}$ \\
\hline Total Phenol & $53.16 \pm 0.65 \mu \mathrm{g} / \mathrm{mg}$ & $77.56 \pm 0.59 \mu \mathrm{g} / \mathrm{mg}$ & $61.34 \pm 0.76 \mu \mathrm{g} / \mathrm{mg}$ & $44.21 \pm 0.53 \mu \mathrm{g} / \mathrm{mg}$ \\
\hline
\end{tabular}

Table 1: Isolated Primary metabolites contents from different plant parts of Tinospora cordifolia. 
Starch is biodegradable and renewable in nature. They are increasingly being considered as an eco-friendly alternative to the use of synthetic additives. During the present research studies, callus of the plant showed higher amount of starch whereas, stem contain moderate whereas root contain lower amount of starch content. This is in agreement with the observations made by Sharma et al. [17] for starch content in Semecarpus anacardium (L). On contrary to this, fruits of Centella asiatica [18] contain maximum amount of starch.

Numerous polysaccharides purified from Chinese medicinal herbs are bioactive and possesses immunomodulating, anti-tumour and antibacterial activities [19]. Proteins are the primary components of living beings. During the present studies, stem contain maximum amount of protein followed by leaf, callus and root in the experimental plant species. Similar result, showing maximum protein content in the stem part was also observed in Commiphora weightii [15]. However on contrary to this, the total amount of protein was found to be higher in seeds [16], Maytenus emarginata and Pongamia pinnata [20,21] and Moringa oleifera [2] respectively.

The biochemistry and medicines are intimately related to health depend on harmonious balance of biochemical reaction occurring in the body, disease reflects abnormalities in biomolecules in biochemical reactions [22]. Phenols have immunomodulating, antitumour, antibacterial activities. In the present studies, different plant parts and in vitro callus of the plant evaluated for total phenol content. It was observed that callus contains maximum amount of phenol as compared to other plant parts. Similarly, Singh et al. [15] also examined the presence of appreciable amount of phenol in in vitro callus culture of Jatropha curcas, Cordia gharaf and Withania Somnifera, respectively. However, in contrast to this, stem contain higher level of phenol in $N$. indicum and has antibacterial and antiinflammatory activities $[4,19]$.

Ascorbic acid (vitamin C) is a familiar molecule because of its dietary significance, it is not only an important antioxidant, but it also appears to linked during flowering time, developmental senescence, programmed cell death and responses to pathogens through a complex signal transduction network. During the present research investigation, ascorbic acid was found maximum in callus and minimum in stem of the plant species. Similar results showing higher amount of ascorbic acid content in callus was also reported by Sharma [23] in Withania somnifera (L.). However, in oppugnancy to this, total levels of ascorbic acid were found to be maximum in leaf and pods of Azadirachta indica [24] and Moringa oleifera [2] respectively [25]. Primary metabolite analysis is necessary for knowing the nutritional potential of plants and their role as precursors for the synthesis of secondary metabolites.

\section{References}

1. Prusti A, Mishra SR, Sahoo S, Mishra SK (2008) Antibacterial activity of some Indian medicinal plants. Ethnobotanical Leaflets 12: 227-230.

2. Talreja $T$ (2011) Biochemical estimation of three primary metabolites from medicinally important plant Moringa oleifera. Int J Pharma Sci Rev Res 7: 186-188.

3. Tatsuta K, Hosokawa S (2006) Total syntheses of bioactive natural products from carbohydrates - A Rev. Sci and Technol Adv Mat 7: 397-410.

4. Vijayvergia R, Kumar J (2007) Quantification of primary metabolites of Nerium indicum Mill. Asian J Exp Sci 21: 123-128.

5. Harada K, Fukusaki E (2009) Profiling of primary metabolite by means of capillary electrophoresis-mass spectrometry and its application for plant science. Plant Biotech 26: 47-52.

6. Yemm EW, Willis AJ (1954) The estimation of carbohydrates in plant extracts by anthrone. Biochem J 57: 508-514.
7. Garth E, Sheila B, Elaine B, Kerr W (1998) Economics of starch production in the 20.

8. Shin-ichiro N, Gerald HT (1998) Ventral mesoderm induction and patterning by bone morphogenetic protein heterodimers in Xenopus embryos. Mechanisms of Development 74: 75-88.

9. Lowry OH, Rosebrough NJ, Farr AL, Randall RJ (1951) Protein measurement with the folin phenol reagent. J of BioChem 193: 265-275.

10. Sadasivam S, Manickam A (1996) Biochemical methods. 2nd edn. New Age International Ltd. Publisher, New Delhi, India, pp: 179-186.

11. Mahadevan A (1965) Biochemistry of resistance in cucumber against Cladosporium cucumerinum-II: The role of cucumber phenols on the growth and secretion of pectinolytic enzyme activity. Indian Phytopath 18: 323-324.

12. Kaufman PB, Cseke LJ, Warber S, Duke JA, Brielmann HL (1998) Natural Products from Plants. CRC Press, Boca Raton, FL, USA, p: 343.

13. Rainha N, Lima E, Baptista J (2011) Comparison of the endemic Azorean Hypericum foliosum with other Hypericum species: antioxidant activity and phenolic profile. Nat Prod Res 25: 123-135.

14. Havsteen $\mathrm{BH}$ (2002) The biochemistry and medical significance of the flavonoids. Pharmacol Ther 96: 67-202.

15. Singh S, Tanwer SB, Khan M (2011) In vivo and in vitro comparative study of primary metabolites of Commiphora wightii (Arnott.) Bhandari. Int J of App Bio and Pharma Tech 2: 162-165.

16. Tanwer BS, Choudhary R, Vijayvergia R (2010) In-vivo and in-vitro comparative study of primary metabolites and antioxidant activity of Andrographis paniculata. J Chem Pharm Res 2: 489-495.

17. Sharma S, Rathi N, Kamal B, Pundir D, Kaur B, et al. (2010) Conservation of diversity of highly important medicinal plants of India through tissue culture technology-a review. Agri Bio J north ame 1: 827-833.

18. Ullah MO, Sultana S, Haque A, Tasmin S (2009) Antimicrobial, Cytotoxic and Antioxidant Activity of Centella asiatica. Euro J of Scientific Res 30: 260-264.

19. Wong RW, Rabie AB (2008) Effect of quercetin on preosteoblasts and bone defects. Open Orthop J 2: 27-32.

20. Sagwan S, Rao DV, Sharma RA (2010) Biochemical estimation of primary metabolites from Pongamia pinnata (L.): An important biodiesel plant. ICP 5: 146-149.

21. Sagwan S, Rao DV, Sharma RA (2010) Phytochemical evaluation and quantification of primary metabolites of Maytenus emarginata (Willd.) Ding Hou. J Chem Pharm Res 2: 46-50.

22. Soga T, Baran R, Suematsu M, Ueno $Y$, Ikeda S, et al. (2006) Differentia metabolomics reveals ophthalmic acid as an oxidative stress biomarker indicating hepatic glutathione consumption. J Biol Chem 281: 16768-16776.

23. Sharma M (2005) In vitro morphogenetic regulation of Withania somnifera (L.). PhD Thesis, University of Rajasthan, Jaipur, India.

24. Shekhawat G (2002) In vitro propagation of Azadirachta indica (L.). PhD Thesis, University of Rajasthan, Jaipur, India.

25. Arnon DI (1949) The estimation of chlorophyll in plants. Plant Physiol J 24: 1-15. 